\title{
What Competences Make Opportunities for Migrants in Russia
}

\author{
Prof. Dr. Irina Grigoryeva \\ St. Petersburg State University \\ 1/3, ul. Smolnogo, 9 entrance, Faculty of Sociology of \\ SPSU, St. Petersburg, 191124, Russian Federation \\ soc28@yandex.ru
}

\author{
Prof. Dr. Irina Sizova \\ St. Petersburg State University \\ 1/3, ul. Smolnogo, 9 entrance, Faculty of Sociology of \\ SPSU, St. Petersburg, 191124, Russian Federation \\ Sociological Institute of FCTAS RAS \\ St. Petersburg, Russia \\ sizovai@mail.ru
}

\begin{abstract}
Modern technological changes (and digitalization in particular) radically change social relations, character of labor and population's employment. A new model of labor and employment, so-called "Job 4.0", brings higher requirements to workers' professional qualifications being applied to all professional groups without exception. Automatized social network analysis was used to analyze online social networks, blogs and forums, search requests in Google and Yandex, and web sites with information addressed to migrants. This analysis was made with a help of IQ Buzz (iqbuzz.ru) -online service for social networks monitoring. A whole informational base of the study (2016-2017) includes more than 100 online-based platforms, which were monitored using key words during several years. As an example, we show the work of Charitable Fund for Support and Development of Educational and Social Projects "PSPFund" in St. Petersburg. NGOs do not train migrants to use ICT (Information and Communication Technologies), because these skills are simply not in demand at the Russian migrant labor market yet.
\end{abstract}

Keywords-Education; Migrants; Competencies for Job 4.0

\section{INTRODUCTION}

Russian society is rather sensitive to migration and is susceptible to migrantophobia. Constant presence in large cities of a large number of foreign-speaking people, even those who are provisionally perceived as foreigners (former fellow citizens of the USSR!), raises concerns for the fate of jobs for the indigenous population. However, migrants usually occupy low-skilled and low-paid jobs, their qualification is far from the requirements of the modern labor market or something similar to "Job 4.0". Experience of implementation of regional and federal migrant programs demonstrates poor effectiveness of such programs. For now, the programs do not affect cultural and, especially, socio-status gap decrease between the Russians and migrants. Obviously, we need sustained and systematic educational or awareness-raising efforts with each of the interacting parties. With migrants, - in respect to their low legal literacy, and with the "receiving" population - in respect to preventing conflicts and practical tolerance.

The resource centers, or competence development centers that conduct educational and organizational work with both migrants and the host population in different areas of mutual adaptation may be the model of such work. Moreover, in keeping with the Russian Federal Law No.442, this work can be carried out not only by public but also by private and social organizations, as the Federal Law has set the task of contracting-out of monopoly of public services in favor of these new forms of service outsourcing for different groups of the population [1].

More than half of the population of the North-West is concentrated in St. Petersburg and the Leningrad region: these territorial entities of the Russian Federation are the second centres of attraction of flows of internal and external migration after Moscow and Moscow region. In such a situation, the issues of maintaining inter-ethnic harmony, integration and adaptation of ethnic minorities, as well as dissemination of principles of tolerance both among ethnic communities and in Russian society as a whole, are becoming increasingly important.

One of the most active organizations working with migrants in the North-West of Russia is the Charity Fund for Support and Development of Educational and Social Projects (PSPFund) [2] in St. Petersburg. The Fund constantly interacts with both the City Government and the organizations providing grants to develop its programs aimed at positive adaptation of migrants and their families. In this article, we present the PSPFund's experience dealing with migrants in recent years.

\section{NGO'S DEALING WITH MigRANTS}

According to the Russian Federal Law No. 442 "Concerning the Basic Principles of Social Services", which came into force on 01.01.2015 and the Concept of the State Migration Policy of the Russian Federation, non-governmental organizations act as an equal and a significant participant in integration processes. One of the tasks of the state in promotion of adaptation and integration of migrants proclaims "the improvement of interaction between federal authorities, state authorities of the territorial entities of the Russian Federation and local self-governing bodies with public associations that promote adaptation and integration of migrants" [3].

Thus, public organizations are one of the main partners of the state in adaptation and integration of migrants. What do and can NGOs do in this sphere? What can be their contribution to 
partnership with government authorities and public agencies, aimed at resolving issues related to the regulation of migration processes? Social organizations, whose target group are migrants, use different approaches in their work. Under the conditions, when increasingly public debates thrive around the problems of migrants' integration, it is understandable that NGOs differentiate their priorities in different ways, organizing their affaires with foreign citizens.

In the sphere of support for migrants, the following main areas of activity of socially oriented NGOs are distinguished:

- immediate direct or humanitarian aid (a small financial support, assistance in providing food, clothing, hygiene accessories and etc.); - legal support and legal advice to labor migrants and members of their families; - assistance in adaptation of migrants in Russian society; - systematical support of organizations dealing with migrants; - expert activity and analytics in the field of migration processes; counteracting xenophobia and promotion of the principles of tolerance among the local population.

Important advantages of NGOs in dealing with migrants are flexibility (the ability to adapt promptly to new challenges and apply new techniques), proximity to the target group and efficiency (the cost of assistance provided by NGOs is often much lower than the same by state institutions).

In the new environment, in foreign country, migrants face lack of information and social ties, they find it difficult to find solutions to the most important issues:

- obtaining of registration and permitting documents;

- finding a job, getting legal advice on specific problems (according to the statistics of St. Petersburg NGOs, most of the migrants' applications are connected with violations of labor rights (illegal employment and non-payment of wages) ;

- Problems with issuance of permits, as well as deportation and inclusion in so-called "black list" (prohibition on entering the Russian Federation).

At the same time, the migrants who face problems are often afraid to reach out to the state, trying to find ways and means of solution of the problems with appeals to social organizations, and only then, with their help, the migrants appeal to government agencies. In this situation, one of the NGO's tasks is to raise the awareness of migrants about opportunities to receive assistance from the state and level of their trust in state institutions. Some NGOs try to solve problems at the system level by participating in development of recommendations aimed at improving legislation and law enforcement practices in sphere of regulation of migration processes. Such activities require high qualification of NGO's employees and, in an ideal scenario, should be based on serious experience of dealing with migrants and knowledge of the problems they face.

At present, the most visible activity in sphere of integration of migrants is the activity of public associations that organize intercultural educational projects, festivals, information campaigns, etc. Such initiatives represent the integration approach in activities of NGOs, as they are oriented not only to migrants, but also on the host community. Within the framework of this approach, the main activities are aimed not only at increasing social and cultural competence of migrants (teaching Russian language, culture, the basics of legal literacy), but also organization of joint civilian activities of migrants and representatives of the local population (participation in the activities of public organizations, volunteering). The activities of such NGOs help to rise competencies migrants and host communities in whole.

\section{EDUCATION AND FUTURE JOB FOR MigRANTS}

Many NGOs of various organizational and legal forms engage in education / training of migrants and their children. These can be preparation courses for admission to educational institutions, courses for studying different languages, for example, and in the Avar, Hebrew, Korean, English, Arabic or Quran tarweed courses. Some NGOs conduct computer literacy classes for adult migrants and their children. However, they are mainly practical skills aimed at developing communication gadgets and financial transactions on the Internet.

A large number of foreign citizens are employed in the Russian economy: in 2017 alone they were granted more than 1.68 million patents for work. In total, at least 4 million migrants work at the same time, of which $95 \%$ are citizens of the CIS countries. Foreigners are involved in such areas of the economy as construction, wholesale and retail trade, utilities, services, manufacturing, etc. The contribution of migrants to certain spheres of the economy is particularly significant - thus, according to experts, foreign migrants are 4.4 times more represented in construction than Russians [5]. For example, in St. Petersburg, at least $36 \%$ of the city's enterprises use foreigners' labor - at that $43.2 \%$ of foreign workers have lowskilled or unskilled positions.

But, as it was already said, migrants work in the branches of traditional employment with predominance of manual labor, without the use of computers. Studies on the nature and level of ICT literacy among migrants in Russia have not yet been conducted. To maintain low-skilled work positions which they mainly occupy, retraining is not required. If the volume of human labor decreases, for example, on assembly lines of car production - mass employment places for migrants, the situation may change. Perhaps, some professions in the sphere of providing social services will be more in demand if services will be provided in the same "manual" mode. Hypothetical consultants developing the scripts of aging are unlikely to be recruited from migrants, although a small proportion of those with medical education are also among them.

Automatized social network analysis was used to analyze online social networks, blogs and forums, search requests in Google and Yandex, and web sites with information addressed to migrants. This analysis was made with a help of IQ Buzz (iqbuzz.ru) -online service for social networks monitoring. A whole informational base of the study (2016-2017) includes more than 100 online -based platforms, which were monitored using key words during several years. Our study demonstrates an increase in the use of mobile devices among migrants for searching information on topics related to job search and money transfer. At the same time, official websites of the Russian Federation Ministry of Labor and Employment and the 
State Services website are very poorly represented in the search results for requests relevant for migrants.

Internet use among migrants mostly aims to communicating in social networks Facebook, Twitter. They use mobile applications such as Viber, Skype, WhatsApp, Instagram and others. But using mobile applications is another kind of practice.

Even the most "advanced" NGOs do not train migrants to use ICT (Information and Communication Technologies), because these skills are simply not in demand at the Russian migrant labor market yet. Some of most advanced, as mentioned above, are the projects and training programs of the PSP-Fund, in particular, because of their international, in different ways, character. So already in 2018 the PSP-Fund has issued several methodological materials for migrants [6]. Of these, there are the following:

- Socio-cultural adaptation of migrants and the development of interethnic dialogue. Methodical recommendations for national cultural organizations. CF "PSPFund", 2018;

- Social assistance, medical assistance, education of children. Handout to help a migrant worker in Uzbek. CF "PSP-Fund", 2017-2018;

- Social assistance, medical assistance, education of children. Handout to help a migrant worker in Tajik. CF "PSPFund", 2017-2018.

\section{CONCLUSION}

In general, for employment of migrants, the growing flexibility of labor market can be a big advantage, especially in this respect, women are win who often combine work with other activities. The flexibility of Russian labor market can mostly be influenced by adjusting to reduction of the work benefits, willingness to overcome bad working conditions or low wages. Perspectives and problems with the development of digital employment are:

1) Accelerated dynamics of the introduction of changes in various aspects of labor and employment, because in older ages, the perception of the new slows down;

2) All aspects of the digitalization of labor and employment (employment on the Internet, work with digital data, use of updated digital assistants and programs, etc.)

3) High workloads and volumes of work, development of soft skills, increase in the autonomy of workers and responsibility for labor;

Attractiveness of Russia for migrants with low and medium qualifications, rather reduces progress towards a modern, hightech economy and "Job 4.0". We suppose, that migrants and their family, especially well-educated and highly qualified women and children may improve the characteristics of the Russian labor market, reduce gender disparity and, indeed, create a new basis for labor market development.

\section{ACKNOWLEDGMENT}

The paper is prepared under the project "Creating a model of a multifunctional centre of competencies in social work with migrants under conditions of their growing inflow in Russia and Switzerland to mitigate threats to society, economy, the state" funded by Ministry of Education and Science of Russian Federation. Project is realized at Saint Petersburg State University under the support of the Federal Target Programme "Research and Development in Top Priority Dimensions of the Science and Technology Complex of Russia in 2014-2020". The Project ID is RFMEFI61317X0072.

\section{REFERENCES}

[1] Federal Law "The Foundations of Social Services in the Russian Federation” N 442-FZ 28.12.2013.

[2] Charity Fund for Support and Development of Educational and Social Projects (PSP-Fund). URL: http://psp-f.org/.

[3] The President approved the Concept of the State Migration Policy of the Russian Federation for the period until 2025. URL: http://kremlin.ru/events/president/news/15635.

[4] All-Russian Azerbaijan Congress website. URL: http://www.vakmos.org/diaspora/regions-vak/murmansk-region/].

[5] Demintseva E.B., N.V. Mkrtchyan, and Yu.V. Florinskaya. Migration policy: diagnostics, challenges, proposals. Moscow: Center for Strategic Research, 2018. - P. 12. URL: https://www.csr.ru/wpcontent/uploads/2018/01/20180126_Report-Migration-Web.pdf.

[6] Publications by PSP-Fund for Migrants. URL: http://pspf.org/publikatsii/migratsiya.html. 